\title{
Bimetallic Palladium Catalysis: Direct Observation of Pd(III)-Pd(III) Intermediates
}

\section{Citation}

Powers, David C., Matthias A. L. Geibel, Johannes E. M. N. Klein, and Tobias Ritter. 2009.

Bimetallic palladium catalysis: Direct observation of Pd(III)-Pd(III) intermediates. Journal of the American Chemical Society 131(47): 17050-17051.

\section{Published Version}

doi:10.1021/ja906935c

\section{Permanent link}

http://nrs.harvard.edu/urn-3:HUL.InstRepos:8156526

\section{Terms of Use}

This article was downloaded from Harvard University's DASH repository, and is made available under the terms and conditions applicable to Open Access Policy Articles, as set forth at http:// nrs.harvard.edu/urn-3:HUL.InstRepos:dash.current.terms-of-use\#OAP

\section{Share Your Story}

The Harvard community has made this article openly available.

Please share how this access benefits you. Submit a story.

Accessibility 


\title{
Bimetallic Palladium Catalysis: Direct Observation of Pd(III)-Pd(III) Intermediates
}

\author{
David C. Powers, Matthias A. L. Geibel, Johannes E. M. N. Klein, and Tobias Ritter \\ Department of Chemistry and Chemical Biology, Harvard University, 12 Oxford Street, Cambridge, MA \\ RECEIVED DATE; ritter@chemistry.harvard.edu
}

$\mathrm{Pd}(\mathrm{II}) / \mathrm{Pd}(\mathrm{IV})$ redox cycles have been proposed for a variety of palladium-catalyzed transformations since 1971., ${ }^{1,2}$ In 2009, bimetallic $\mathrm{Pd}(\mathrm{III})$ intermediates were put forth as a mechanistic alternative to the frequently invoked $\mathrm{Pd}(\mathrm{II}) / \mathrm{Pd}(\mathrm{IV})$ redox cycles. $^{3} \quad$ Our account disclosed previously unrecognized reactions from organometallic $\mathrm{Pd}(\mathrm{III})$ complexes, but did not provide evidence for the generality of bimetallic $\mathrm{Pd}(\mathrm{III})$ intermediates in catalysis. Here we report the first direct observation of bimetallic $\mathrm{Pd}(\mathrm{III})$ complexes in $\mathrm{C}-\mathrm{H}$ acetoxylation reactions. The $\mathrm{Pd}(\mathrm{III})$ intermediates are obtained by oxidation of $\mathrm{Pd}(\mathrm{II})$ catalysts with one of the most common oxidants for oxidative palladium catalysis-- $\mathrm{PhI}(\mathrm{OAc})_{2}$. Our results demonstrate that bimetallic $\mathrm{Pd}(\mathrm{III})$ complexes should be considered as relevant reaction intermediates in a class of Pdcatalyzed reactions previously suggested to proceed via $\mathrm{Pd}(\mathrm{II}) / \mathrm{Pd}(\mathrm{IV})$ redox cycles. ${ }^{2}$

$\mathrm{Pd}$-catalyzed aromatic $\mathrm{C}-\mathrm{H}$ acetoxylation was first reported in $1966 .{ }^{4}$ In acetic acid, oxidants such as $\mathrm{K}_{2} \mathrm{Cr}_{2} \mathrm{O}_{7}, \mathrm{~Pb}(\mathrm{OAc})_{4}$, and $\mathrm{N}_{2} \mathrm{O}_{2}$ oxidize benzene to phenyl acetate under Pd catalysis. ${ }^{5}$ Stock proposed a $\mathrm{Pd}(\mathrm{II}) / \mathrm{Pd}(\mathrm{IV})$ mechanism for this class of reactions in $1981 .^{6}$ Crabtree reported the first $\operatorname{Pd}(\mathrm{OAc})_{2}$ catalyzed acetoxylation of arenes with the terminal oxidant $\mathrm{PhI}(\mathrm{OAc})_{2}$ (eq 1). ${ }^{7} \quad$ Since 2004, Sanford $^{8}$ and $\mathrm{Yu}^{9}$ have pioneered practical, directed $\mathrm{C}-\mathrm{H}$ acetoxylation reactions that also employ $\mathrm{Pd}(\mathrm{OAc})_{2}$ as catalyst. Reductive elimination from well-defined $\mathrm{Pd}(\mathrm{IV})$ complexes, shown for $\mathrm{C}-\mathrm{C}$ bond formation by Canty ${ }^{10}$ and for $\mathrm{C}-\mathrm{O}$ bond formation by Sanford, ${ }^{11}$ has been observed. However, the relevance of Pd(IV) complexes to Pdcatalyzed acetoxylation has not been established.

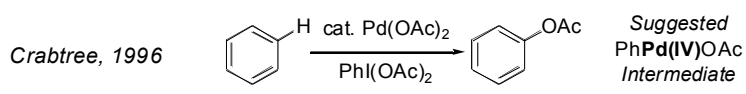

While several bimetallic complexes of $\mathrm{Pt}(\mathrm{III})$ have been reported, ${ }^{12}$ only few organometallic $\mathrm{Pd}(\mathrm{III})$ complexes have been described: five paddlewheel complexes by Cotton and Lahuerta, ${ }^{13}$ and five carboxylate-bridged bimetallic complexes by us. ${ }^{3} \quad$ We have shown that reductive elimination from bimetallic $\mathrm{Pd}(\mathrm{III})$ complexes can form carbon-heteroatom bonds, and implicated bimetallic palladium complexes in catalysis through kinetic analysis. However, when oxidants such as NCS were employed, proposed bimetallic Pd(III) complexes were not observed during catalysis. To evaluate the potential generality of bimetallic $\mathrm{Pd}(\mathrm{III})$ complexes as intermediates in catalysis, we studied the oxidation of $\mathrm{Pd}(\mathrm{II})$ catalysts with $\mathrm{PhI}(\mathrm{OAc})_{2}$, one of the most common oxidants for Pd-catalyzed $\mathrm{C}-\mathrm{H}$ bond functionalizations. ${ }^{2}$

Cyclopalladation, first reported by Cope in $1965,,^{14}$ of 2 phenylpyridine (1) with $\mathrm{Pd}(\mathrm{OAc})_{2}$, afforded the bimetallic $\mathrm{Pd}(\mathrm{II})$ complex 2, in which the two palladium nuclei are held in proximity by bridging acetate ligands (Scheme 1). When bimetallic $\mathrm{Pd}(\mathrm{II})$ complex 2 was treated with $\mathrm{PhI}(\mathrm{OAc})_{2}$ at
Scheme 1. Discrete Bimetallic $\mathrm{Pd}(\mathrm{III})$ Intermediate in Acetoxylation.

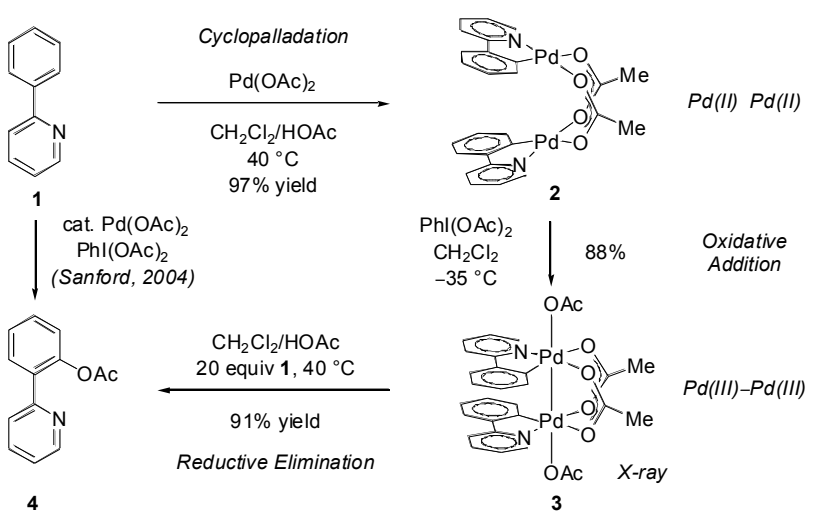

$-35^{\circ} \mathrm{C}$, the thermally sensitive bimetallic $\mathrm{Pd}(\mathrm{III})$ complex $\mathbf{3}$ was observed, and could be isolated in $88 \%$ yield. Complex $\mathbf{3}$ is stable in solution and in the solid state below $-10{ }^{\circ} \mathrm{C}$ and was characterized crystallographically (Figure 1).

Bimetallic $\mathbf{3}$ is not the catalyst resting state and cannot be observed during catalysis. However, we observed the formation and reaction of $\mathbf{3}$ under pseudocatalytic conditions by sequential addition of reagents at controlled temperatures. We treated $\mathrm{Pd}(\mathrm{OAc})_{2}$ with excess substrate $\mathbf{1}$ and observed the dimer $\mathbf{2}$ in the presence of five equivalents of $\mathbf{1} .^{15}$ Subsequent addition of five equivalents $\mathrm{PhI}(\mathrm{OAc})_{2}$ at $-10{ }^{\circ} \mathrm{C}$ afforded the $\mathrm{Pd}(\mathrm{III})$ dimer 3 in $66 \%$ yield. ${ }^{16}$ Upon warming the purified intermediate 3 in the presence of 20 equiv of substrate 1 to $40{ }^{\circ} \mathrm{C}$, bimetallic reductive elimination occurred to afford product 4 in $91 \%$ yield. Reductive elimination from $\mathbf{3}$ in the absence of $\mathbf{1}$ afforded product 4 in only $6 \%$ yield. Likewise, the $\mathrm{Pd}(\mathrm{OAc})_{2}$-catalyzed reaction 14 with $100 \mathrm{~mol} \% \mathrm{Pd}$ did not afford 4 upon heating at $80^{\circ} \mathrm{C}$ for $12 \mathrm{~h}$. Both results suggest the consumption of product 4 by Pd after reductive elimination. ${ }^{17}$

After reductive elimination from $\mathbf{3}$ in the presence of $\mathbf{1}$, the bimetallic Pd(II) complex $\mathbf{2}$ was observed by ${ }^{1} \mathrm{H}$ NMR. Reductive elimination by first order kinetics in bimetallic $\mathrm{Pd}(\mathrm{III})$ complex was established by following product formation from a methylated analog of $\mathbf{3}$ for accurate ${ }^{1} \mathrm{H}$ NMR integration. All reactions shown in Scheme 1 can be carried out in $\mathrm{CH}_{2} \mathrm{Cl}_{2}$ or $\mathrm{AcOH}$ or a mixture thereof. The isolation of $\mathbf{3}$, however, required addition of $\mathrm{CH}_{2} \mathrm{Cl}_{2}$ because 3 was not stable at the freezing point of $\mathrm{AcOH}\left(17{ }^{\circ} \mathrm{C}\right)$ or above. Observation of both oxidation of 2 with $\mathrm{PhI}(\mathrm{OAc})_{2}$ and reductive elimination from 3 to $\mathbf{4}$ is consistent with the participation of bimetallic $\mathrm{Pd}(\mathrm{III})$ intermediates in the $\mathrm{Pd}$-catalyzed $\mathrm{C}-\mathrm{H}$ functionalization of arenes with the oxidant $\mathrm{PhI}(\mathrm{OAc})_{2}$.

Discrete monometallic Pd(IV) complexes such as 5 (Figure 1) have been considered as models for the high-valent palladium complexes, from which $\mathrm{C}-\mathrm{O}$ reductive elimination could occur during catalysis. ${ }^{1 \mathrm{~b}} \mathrm{We}$ measured the initial rate of the reaction 


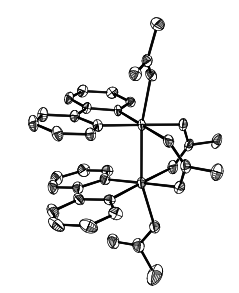

X-ray structure of $\mathbf{3}$, Pd-Pd bond: 2.5548(5) A

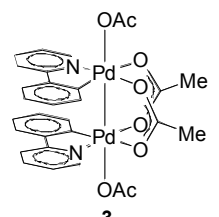

3

$P d(I I I)-P d(I I I) 3$

kinetically competent

for catalysis

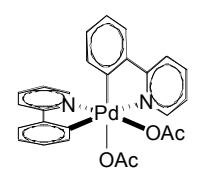

5

Pd(IV) 5 not for catalysis kinetically competent

Figure 1. ORTEP diagram of $\mathrm{Pd}(\mathrm{III}) 3$ with ellipsoids drawn at $50 \%$ probability level; kinetic competence of $\mathbf{3}$ and $\mathbf{5}$.

from 1 to 4 (shown on the left of Scheme 1) catalyzed by 8 mol\% $\mathrm{Pd}(\mathrm{OAc})_{2}, 8 \mathrm{~mol} \%$ monometallic $\mathrm{Pd}(\mathrm{IV}) \mathbf{5}$, and $4 \mathrm{~mol} \%$ bimetallic $\mathrm{Pd}(\mathrm{III}) \mathbf{3}$, respectively. The initial rate of product formation with catalyst $\mathbf{5}$ was half as fast as the initial rate with $\mathrm{Pd}(\mathrm{OAc})_{2}$ as catalyst. Therefore, the $\mathrm{Pd}(\mathrm{IV})$ complex $\mathbf{5}$ is not kinetically competent for catalysis. The initial rate of product formation with bimetallic $\mathrm{Pd}(\mathrm{III})$ complex 3 is faster than the rate observed with $\mathrm{Pd}(\mathrm{OAc})_{2}$, which demonstrates that $\mathbf{3}$ is kinetically competent for catalysis. Observation and kinetic competence of $\mathbf{3}$, as well as the kinetic incompetence of $\mathbf{5}$, cannot exclude the potential transient intermediacy of $\mathrm{Pd}(\mathrm{IV})$ complexes other than 5. For example, our data cannot rule out the formation and relevance to catalysis of monoaryl Pd(IV) complexes.

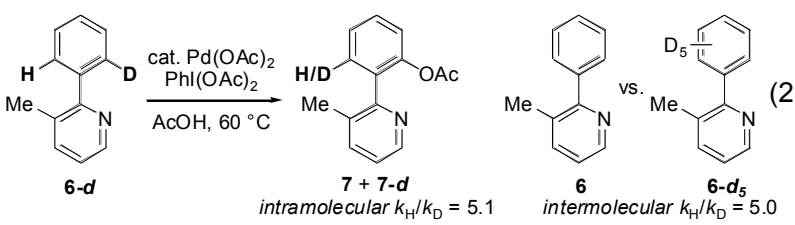

Kinetic analysis under conditions of catalysis, isolation of both $\mathbf{2}$ and $\mathbf{3}$, as well as the independent observation of all three fundamental reactions - bimetallic oxidative addition, bimetallic reductive elimination, and cyclometallation - is consistent with the proposed catalytic cycle shown in Figure 2. Measurement of the initial rate of acetoxylation as a function of $\mathrm{PhI}(\mathrm{OAc})_{2}$ concentration showed a zero order kinetic dependence in oxidant, which precludes rate-determining oxidation. Observation of an intramolecular primary kinetic isotope effect of $k_{\mathrm{H}} / k_{\mathrm{D}}=5.1$ and an intermolecular primary isotope effect of $k_{\mathrm{H}} / k_{\mathrm{D}}=5.0$ is consistent with rate-determining cyclopalladation. $^{18}$ The isotope effects were determined by acetoxylation of substrate $\mathbf{6}-\boldsymbol{d}$ and by competing acetoxylation between $\mathbf{6}$ and $\mathbf{6}-\boldsymbol{d}_{\boldsymbol{5}}$ (eq 2, see Supporting Information). Ratedetermining cyclometallation precludes the kinetic implication of bimetallic Pd complexes during oxidation and reductive elimination; however, bimetallic palladium complexes were implicated in the rate-determining step of related $\mathrm{C}-\mathrm{H}$ oxidations with weaker oxidants than $\mathrm{PhI}(\mathrm{OAc})_{2}$, in which case cyclopalladation is not rate-determining. ${ }^{3,19}$

In conclusion, our report discloses the first evidence of bimetallic Pd(III) intermediates in Pd-catalyzed acetoxylation. Based on this evidence and our previous kinetic implication of a bimetallic $\mathrm{Pd}$ complex in the rate-determining step of $\mathrm{C}-\mathrm{H}$ functionalization with NCS, we propose that bimetallic $\mathrm{Pd}(\mathrm{III})$ complexes are responsible for a large class of $\mathrm{C}-\mathrm{H}$ oxidations, previously proposed to proceed via $\mathrm{Pd}(\mathrm{II}) / \mathrm{Pd}(\mathrm{IV})$ redox cycles.

Acknowledgement. We thank Peter Müller for X-ray crystallographic analysis and Sanofi-Aventis for a graduate fellowship for DCP.

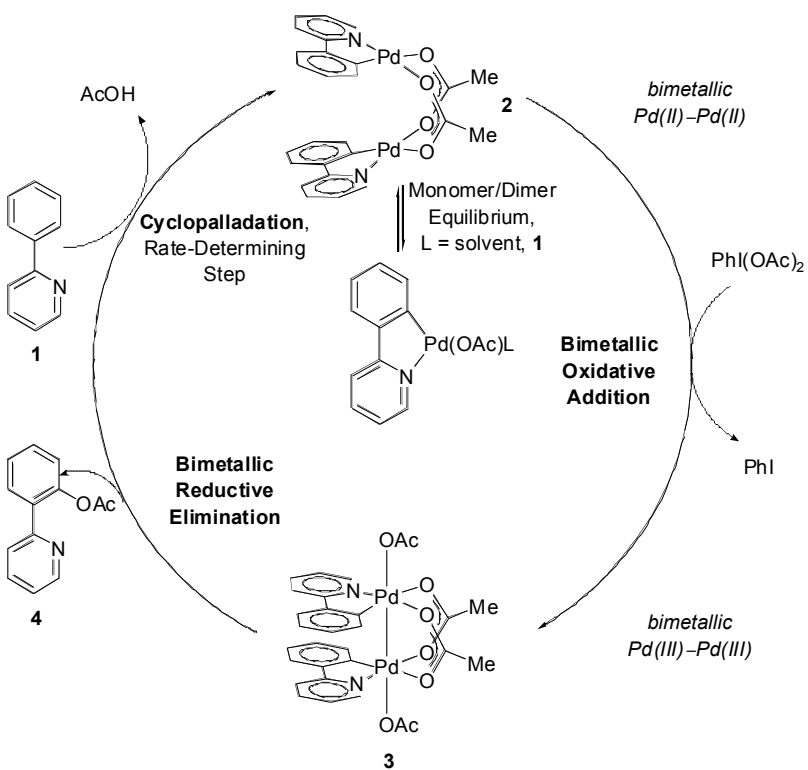

Figure 2. Proposed bimetallic $\mathrm{Pd}(\mathrm{II}) / \mathrm{Pd}(\mathrm{III})$ catalytic cycle.

Supporting Information Available: Detailed experimental procedures and spectroscopic data for all new compounds. This material is available free of charge via the Internet at http://pubs.acs.org.

\section{REFERENCES}

[1] Henry, P. M. J. Org. Chem. 1971, 36, 1886-1890.

[2] Kalyani, D.; Dick, A. R.; Anani, W. Q.; Sanford, M. S. Tetrahedron 2006, 62, 11483-11498.

[3] Powers, D. C.; Ritter, T. Nat. Chem 2009, 1, 302-309.

[4] Davidson, J. M.; Triggs, C. Chem. Ind. 1966, 457.

[5] (a) Tisue, T.; Downs, W. J. J. Chem Soc. D; Chem. Commun. 1969 410a; (b) Henry, P. M. Palladium Catalyzed Oxidation of Hydrocarbons, vol. 2. In Catalysis by Metal Complexes; Ugo, R., James, B. R., Eds., D. Reidel Publishing Company: Boston, MA, 1980; pp 310-312.

[6] Stock, L. M.; Tse, K.-T.; Vorvick, L. J.; Walstrum, S. A. J. Org. Chem 1981, 46, 1759-1760.

[7] Yoneyama, T.; Crabtree, R. H. J. Mol. Cat. A 1996, 108, 35-40.

[8] (a) Dick, A. R.; Hull, K. L.; Sanford, M. S. J. Am. Chem. Soc. 2004 126, 2300-2301; (b) Kalyani, D.; Sanford, M. S. Org. Lett. 2005, 7 4149-4152; (c) Desai, L. V.; Stowers, K. J.; Sanford, M. S. J. Am Chem. Soc. 2008, 130, 13285-13293.

[9] Giri, R.; Liang, J.; Lei, J.-G.; Li, J.-J.; Wang, D.-H.; Chen, X.; Naggar, I. C.; Guo, C.; Foxman, B. M.; Yu, J.-Q. Angew. Chem. Int. Ed. 2005, 44, 7420-7424

[10] Byers, P. K.; Canty, A. J.; Skelton, B. W.; White, A. H. J. Chem. Soc. Chem. Commun. 1986, 1722-1724.

[11] (a) Dick, A. R.; Kampf, J. W.; Sanford, M. S. J. Am. Chem. Soc. 2005 127, 12790-12791; (b) Racowski, J. M.; Dick, A. R.; Sanford, M. S. J. Am. Chem. Soc. 2009, 131, 10974-10983.

[12] (a) Roundhill, D. M.; Gray, H. B.; Che, C.-M. Acc. Chem. Res. 1989 22, 55-61; (b) Dick, A. R.; Kampf, J. W.; Sanford, M. S. Organometallics 2005, 24, 482-485; (c) Canty, A. J.; Gardiner, M. G.; Jones, R. C.; Rodemann, T.; Sharma, M. J. Am. Chem. Soc. 2009, 131, 7236-7237.

[13] (a) Cotton, F. A.; Gu, J.; Murillo, C. A.; Timmons, D. J. J. Am. Chem. Soc. 1998, 120, 13280-13281; (b) Cotton, F. A.; Koshevoy, I. O.; Lahuerta, P.; Murillo, C. A.; Sanaú, M; Ubeda, M. A.; Zhao, Q. J. Am. Chem. Soc. 2006, 128, 13674-13675;. (c) Penno, D.; Lillo, V.; Koshevoy, I. O.; Sanaú, M.; Ubeda, M. A.; Lahuerta, P.; Fernández, E. Chem. Eur. J. 2008, 14, 10648-10655

[14] Cope, A. C.; Siekman, R. W. J. Am. Chem. Soc. 1965, 87, 3272-3273.

[15] Cyclometallated Pd(II) complexes such as $\mathbf{2}$ are in equilibrium with monometallic $\mathrm{Pd}$ (II) complexes bearing an additional ligand: Ryabov, A. D. Inorg. Chem 1987, 26, 1252-1260.

[16] Addition of 1 equiv $\mathrm{PhI}(\mathrm{OAc})_{2}$ to $\mathbf{2}$ afforded $\mathbf{3}$ in $88 \%$ isolated yield. In the presence of excess $\mathbf{1}$ and $\mathrm{PhI}(\mathrm{OAc})_{2}$, the thermally sensitive $\mathrm{Pd}(\mathrm{III})$ dimer 3 could not be isolated without reductive elimination to 4 The yield of $66 \%$ was determined by ${ }^{1} \mathrm{H}$ NMR spectroscopy using an internal standard.

[17] Acetoxylation of 1 with $\mathrm{PhI}(\mathrm{OAc})_{2}$ with 100 mol\% $\mathrm{Pd}(\mathrm{OAc})_{2}$ proceeded in $0 \%$ yield. The yield of $\mathbf{4}$ increased when $50 \mathrm{~mol} \%$ $\mathrm{Pd}(\mathrm{OAc})_{2}$ was used. The yield of $\mathbf{4}$ from $\mathbf{3}$ in the absence of $\mathbf{1}$ could be increased from $6 \%$ to $82 \%$ by addition of 20 equiv of pyridine prior to reductive elimination. For details, see Supporting Information.

[18] Stowers, K. J.; Sanford, M. S. Org. Lett. 2009, 11, 4584-4587.

[19] Deprez, N. R.; Sanford M. S. J. Am. Chem. Soc. 2009, 131, 11234 11241 . 


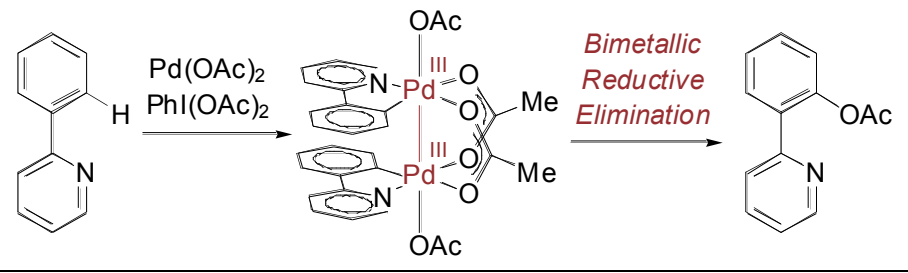

$\mathrm{Phl}(\mathrm{OAc})_{2}$ is a common oxidant for Pd-catalyzed C-H bond functionalizations. Mechanistic hypotheses since the 1960's have suggested a $\mathrm{Pd}(\mathrm{II}) / \mathrm{Pd}(\mathrm{IV})$ mechanism. Here we present evidence for the relevance of bimetallic Pd(III) complexes to catalysis. A bimetallic $\mathrm{Pd}(\mathrm{III})$ acetate was isolated and can afford product by bimetallic reductive elimination. 